\title{
Morphometric Study of Jugular Foramen
}

\section{Shruthi B.N 1, Pavan P. Havaldar 2, Shaik Hussain Saheb *3, Henjarappa K S 4 .}

${ }^{1}$ Associate Professor, Department of Anatomy, Raja Rajeswari Medical College \& Hospital, Bengaluru, Karnataka, India.

${ }^{2}$ Associate Professor, Department of Anatomy, Gadag Institute of M edical Sciences, Gadag, India.

${ }^{* 3}$ Assistant Professor, Department of Anatomy, JJM M edical College, Davangere, Karnataka, India.

${ }^{4}$ Assistant professor, Department of Anesthesia, Kidwai M emorial Institute Of Oncology, Bangalore, Karnataka, India.

\section{ABSTRACT}

Background: The jugular foramen is difficult to understand and to access surgically, Its is difficult to conceptualize because it varies in size and shape in different crania, from side to side in the same cranium, from its intracranial to extra cranial end in the same foramen, because of its complex irregular shape, its curved course, its formation by two bones, and the numerous nerves and venous channels that pass through it. The morphometric measurements of the jugular foramen is very helpful in neurosurgery.

Materials and M ethods: A total of 500 jugular foramina were examined from 250 adult dry skulls. The present study was undertaken in adult south Indian skulls from different regions of south India, from different medical colleges. We have observed the length, width and area of the jugular foramina were determined. Metric measurements were taken by using Vernier calipers. The mean standard deviation and range of each dimension and derived index were computed. Right and left side differences were analysed.

Results: In $71.2 \%$ of cases the right foramina were larger than the left, in $20.8 \%$ of cases the left foramina were larger than the right and in $8 \%$ cases they were equal in size on both sides. The mean length of the foramen on the right and left were $24.48 \pm 3.17 \mathrm{~mm}$ and $21.24 \pm 4.51 \mathrm{~mm}$; the width measured $7.51 \pm 1.56 \mathrm{~mm}$ and $7.16 \pm 1.89 \mathrm{~mm}$ on the right and left respectively; the mean area on the right was $569.41 \pm 91.58 \mathrm{cmm}$ and on the left $470.40 \pm 115.45 \mathrm{~mm}$.

Conclusion: There was statistical significance between the two sides in the length and area but there was no significant difference between the two sides in the width. There was a positive correlation between length and width on each side. Statistical analysis did show significant positive correlation between the width and length of the skull and the length of the jugular foramen on both sides.

KEY WORDS: Skull, Jugular foramen, Anatomy, M orphometry, Neurosurgery.

Address for correspondence: Shaik Hussain Saheb, Assistant Professor, Department of Anatomy, JJM M edical College, Davangere, India. Mobile no.: +919242056660

E-Mail: anatomyshs@gmail.com

\begin{tabular}{|c|c|c|}
\hline \multicolumn{3}{|c|}{ Online Access and Article Informtaion } \\
\hline \multirow{2}{*}{ Quick Response code } & \multicolumn{2}{|c|}{$\begin{array}{l}\text { International Journal of Integrative Medical Sciences } \\
\qquad \text { www.imedsciences.com }\end{array}$} \\
\hline & $\begin{array}{l}\text { Received: 15-09-2015 } \\
\text { Reviewed: 16-09-2015 }\end{array}$ & $\begin{array}{l}\text { Accepted: } 10-10-2015 \\
\text { Published: } 10-11-2015\end{array}$ \\
\hline Source of Funding: Self & \multicolumn{2}{|c|}{ Conflicts of interest: None } \\
\hline
\end{tabular}

\section{INTRODUCTION}

Jugular foramen is a large aperture in the base of the skull. It is located behind the carotid canal and is formed by the petrous part of the temporal bone and behind by the occipital bone.
The jugular foramen is the main route of venous outflow from the skull and is characterized by laterality based on the predominance of one of the sides. Sigmoid sinus continues as internal jugular vein in posterior part of jugular foramen. 
Ligation of the internal jugular is sometimes performed during radical neck dissection with the risk of venous infarction, which some adduce to be due to ligation of the dominant internal jugular vein [1]. It is generally said that although the Jugular foramen is larger on the right side compared to the left, its size as well as its height and volume vary in different racial groups and sexes. The foramen's complex shape, its formation by two bones, and the numerous nerves and venous channels that pass through it further compound its anatomy [2,3].

Intracranial and extra cranial lesions may affect the jugular foramen in addition to intrinsic abnormalities. Pathological processes affecting jugular foramen include intracranial meningioma, schwannomas, metastatic lesions and infiltrative inflammatory processes from surrounding structures such as the middle ear [4]. undertaken in adult south Indian skulls from different regions of south India, from different medical colleges. The length, width and area of the jugular foramina were determined. Measurements were taken by using Vernier calipers. The mean standard deviation and range of each dimension and derived index were computed. Right and left side differences were analysed.

\section{RESULTS}

The mean length of the foramen on the right and left were $24.48 \pm 3.17 \mathrm{~mm}$ and $21.24 \pm 4.51$ $\mathrm{mm}$; the width measured $7.51+1.56 \mathrm{~mm}$ and $7.16+1.89 \mathrm{~mm}$ on the right and left respectively; the mean area on the right was 569.41 $\pm 91.58 \mathrm{cmm}$ and on the left $470.40 \pm 115.45 \mathrm{~mm}$ (Table. 1).The size of the jugular foramen varied on the two sides.

Table 1: Dimensions of the jugular foramen.

\begin{tabular}{|l|c|c|c|c|c|c|}
\hline & Rt L & Lt L & Rt W & Lt W & Rt A & Lt A \\
\hline Mean $₫$ SD & $24.48 \pm 3.17$ & $21.24 \pm 4.51$ & $7.51 \pm 1.56$ & $7.16 \pm 1.89$ & $569.41 \pm 91.58$ & $470.40 \pm 115.45$ \\
\hline Minimum & 20.23 & 16.54 & 5.32 & 4.5 & 444.58 & 250.18 \\
\hline Maximum & 29.16 & 26.95 & 9.88 & 9.67 & 701.09 & 594.37 \\
\hline
\end{tabular}

Rt L - right length, Lt L- left length, Rt W - right width, LTW - left width, Rt A- right area, Lt A - left area, $\mathrm{SD}$ - standard deviation. All measurements in $\mathrm{mm}$

Surgical resection is the treatment of choice in the majority of these cases. Advances in microsurgical techniques have made possible the removal of advanced Jugular foramen lesions, which were once assumed to be inoperable [5]. As neurosurgeons become bolder in approaching this region, so the need for familiarity with the detailed anatomy of this region becomes greater. In Vasalius [6] book De Humani Corporis Fabrica it is mentioned that there are only three illustrations of the base of the skull. Two are identical apart from the labelling, and the left jugular foramen is much larger than the right. The third illustration is that of a skull held by a skeleton and the details of the base are indistinct, but the right jugular foramen appears to be larger than the left. The present study was conducted to study the morphometry of jugular foramen, significance between sizes of right and left foramen.

\section{MATERIALS AND METHODS}

A total of 500 jugular foramina were examined from 250 adult dry skulls. The present study was
In the present study of 250 skulls right jugular foramen greater than left were $178(71.2 \%)$, right jugular foramen lesser than left were $52(20.8 \%)$, right jugular foramen equal to left were 20(8\%).

\section{DISCUSSION}

The size and shape of the jugular foramen is obviously related to the size of the internal jugular vein and the presence or absence of a prominent superior bulb. The right foramen is usually larger than the left. There is a very wide variation in the anatomy of the intra cranial venous sinuses which accounts for variation in size and shape of jugular foramen. The difference in size of the two internal jugular veins is already visible in the human embryo at the 23 $\mathrm{mm}$ stage and probably results from differences in the pattern of development of the right and left brachiocephalic veins.

In present study the mean length of the foramen on the right and left were $24.48 \pm 3.17 \mathrm{~mm}$ and $21.24 \pm 4.51 \mathrm{~mm}$; the width measured $7.51 \pm 1.56$ $\mathrm{mm}$ and $7.16 \pm 1.89 \mathrm{~mm}$ on the right and left 
respectively; the mean area on the right was $569.41 \pm 91.58 \mathrm{~mm}$ and on the left $470.40 \pm$ $115.45 \mathrm{~mm}$ (Table. 1). The size of the jugular foramen varied on the two sides. In the present study of 250 skulls right jugular foramen greater than left were $178(71.2 \%)$, right jugular foramen lesser than left were 52(20.8\%), right jugular foramen equal to left were $20(8 \%)$.

In study of Roma Patel and C.D.M ehta [7] the mean transverse diameter of jugular foramen on the right and left were $12.17 \mathrm{~mm}$ (range: $4.5-$ $16.5 \mathrm{~mm}$ and $11 \mathrm{~mm}$ (range: $5-16 \mathrm{~mm}$ ) respectively, while their sagittal diameter measured $7.9 \mathrm{~mm}$ (range:3-12.5 mm) and $6.2 \mathrm{~mm}$ (range: $3-12.5 \mathrm{~mm}$ ) on the right and left respectively. Both diameters are more on right side. In the study done by Idowu on Nigerian skull, he found mean transverse diameter of jugular foramen on the right and left were $13.90 \mathrm{~mm}$ (11.6-17.0 $\mathrm{mm})$ and $14.11 \mathrm{~mm}(9.2-20.2 \mathrm{~mm})$, while their sagittal diameter measured $10.22 \mathrm{~mm}(6.8-14.4$ $\mathrm{mm})$ and $9.57 \mathrm{~mm}(7.4-12.8 \mathrm{~mm})$ on the right and left respectively [8]. According to study done on turks skull by Ekinci and Unur, the sagittal and transverse diameters of the left jugular foramen were 7.6 and $15.5 \mathrm{~mm}$, respectively, and on the right $8.4 \mathrm{~mm}$ and $16 \mathrm{~mm}$, respectively [9]. Pereira, GAM . studied total 111 skulls (of southern Brazil) and it was noticed that mean transverse diameter was $15.82 \mathrm{~mm}$ on right side and $15.86 \mathrm{~mm}$ on left side; mean sagittal diameter was $9.21 \mathrm{~mm}$ on right side and $8.65 \mathrm{~mm}$ on left side [10]. In study of Hussain Saheb et al [11] it was found that the mean length of jugular foramen on the right and left were $23.62 \mathrm{~mm}$ and $22.86 \mathrm{~mm}$, while their widths measured $7.83 \mathrm{~mm}$ and $6.83 \mathrm{~mm}$ respectively. The mean area on the right was $584.36 \mathrm{~mm}$ and on the left was $493.30 \mathrm{~mm}$. Predominance of one of the two foramina appeared in $89.6 \%$ of cases. Predominance on the right was $64.8 \%$ and $24.8 \%$ on the left. $10.4 \%$ cases were equal on both sides.

\section{CONCLUSION}

The present study observed variation in the size of jugular foramen sizes. The foramen are larger on the right than the left in Indian population. The morphometric sizes of jugular foramen may help in neurosurgeons in their clinical practice.

\section{REFERENCES}

[1]. Wysocki J, Chmielik LP, Gacek W. Variability of magnitude of the human jugular foramen in relation condition of the venous outflow after ligation of the internal jugular vein. J Otolaryngologia 1999;53:173-77.

[2]. Navsa N, Kramer B. A quantitative assessment of the jugular foramen. Anatomischer Anzeiger 1998;180:269-73.

[3]. Hovelacque A. Osteologie. Paris. 1967;155-56.

[4]. Kanemoto $Y$, Ochiai C, Yoshimoto $Y$, Nagai M. Primarily extracranial jugular foramen neurinoma manifesting with marked hemiatrophy of the tongue: case report. Surg Neurol. 1998 May;49(5):534-37

[5]. Woodhall B. Anatomy of the cranial blood sinuses with particular reference to the lateral. Laryngoscope 1939;49;966-1010.

[6]. VESALIUS, A. De Humani Corporis Fabrica. Basel: Oporinus 1543.

[7]. Roma Patel, C.D. Mehta. Morphometric study of Jugular Foramen at base of the skull in South Gujarat region. IOSR Journal of Dental and M edical Sciences. 2014; 9: 58-61.

[8]. Idowu OE. The jugular foramen-A morphometric study. Folia Morphol 2004;63:419-22.

[9]. Ekinci N., Unur E. M acroscopic and morphometric investigation of the jugular foramen of the human skull. J Anatomy 1997;72:525-29.

[10]. Pereira GAM , Lopes PTC, Santos AM PV, Krebs WD. Morphometric aspects of the jugular foramen in dry skulls of adult individuals in Southern Brazil. J.Morphol. Sci. 2010;27:3-5.

[11]. Hussain Saheb S, Mavishetter G F, Thomas S T, Prasanna LC, M uralidhar P. A M orphometric study of the jugular foramen in human adult skulls of south India. J Biomed Sci and Res., 2010;2(4):240243.

\section{How to cite this article:}

Shruthi B.N, Pavan P. Havaldar, Shaik Hussain Saheb, Henjarappa K S. M orphometric Study of Jugular Foramen. Int J Intg Med Sci 2015;2(10):164-166. DOI: 10.16965/ ijims.2015.126 